\title{
Abordagem sobre trabalho artesanal em histórias de vida de mulheres ${ }^{1}$
}

\section{Approach on handmade work in women life stories}

\author{
Márcia Alves da Silva²
}

\begin{abstract}
RESUMO
Este texto refere-se a um projeto de pesquisa em andamento, que busca investigar o processo de construção dos sentidos do trabalho feminino e sua relação com a categorização de gênero a partir das histórias de vida de mulheres artesãs e da produção artesanal produzida por cada participante. Um grupo participante é formado por mulheres artesãs pertencentes a uma cooperativa de arte e artesanato popular e o outro por discentes de cursos de licenciaturas da Universidade Federal de Pelotas (UFPel), especialmente dos cursos de Pedagogia e Artes Visuais. A iniciativa buscou construir um espaço de produção artesanal, onde as memórias são resgatadas não apenas a partir da oralidade, mas também na produção concreta do artesanato, através do que denominamos de Oficinas de Criação Coletiva.
\end{abstract}

Palavras-chave: gênero; arte-educação; histórias de vida; trabalho feminino.

\begin{abstract}
This text refers to an ongoing research project that seeks to investigate the process of constructing meanings of women's work and its relation to gender categorization from the life stories of artisan women and from craft production produced by each participant. A participant group is formed by artisan women belonging to an art and craft popular cooperative and the other is formed by students of undergraduate courses of Universidade Federal de Pelotas (UFPel), specially of Pedagogy and Visual Arts courses.
\end{abstract}

DOI: $10.1590 / 0104-4060.36810$

1 Projeto de pesquisa denominado "Artesã e professora: aproximações entre trabalho feminino e docência", financiado pelo Conselho Nacional de Desenvolvimento Científico e Tecnológico - CNPq entre 2012 e 2013.

2 Universidade Federal de Pelotas. Faculdade de Educação. Pelotas, Rio Grande do Sul, Brasil. Rua Alberto Rosa, n 154. CEP: 96010-770. 
The initiative sought to build a craft production space, where memories are redeemed not only from orality, but also in craft concrete production, through what we call Collective Creation Workshops.

Keywords: gender; art-education; life stories; female labor.

\section{Introdução}

Este texto se refere a uma investigação que temos encaminhado, financiada pelo Conselho Nacional de Desenvolvimento Científico e Tecnológico - CNPq, e que tem como objetivo investigar o processo de construção das identidades de gênero a partir do relato de vivências de mulheres artesãs no mundo do trabalho, basicamente do trabalho artesanal. Dois grupos de mulheres têm feito parte da pesquisa: um grupo formado por mulheres artesãs vinculadas a uma cooperativa localizada na cidade de Pelotas e outro de acadêmicas do curso de Pedagogia da Universidade Federal de Pelotas (UFPel) que produzem artesanato. Nossa investigação aborda as trajetórias de vidas das mulheres pertencentes aos dois grupos, estabelecendo uma aproximação e um diálogo entre ambos, tendo o artesanato como um vínculo em comum.

Basicamente levantamos as seguintes questões investigativas: o trabalho artesanal pode ser uma ferramenta para um processo de emancipação feminina no que se refere ao mundo do trabalho? Em que medida a arte contribui para um processo ético-estético de construção e qualificação de sentidos profissionais e existenciais, ressignificando as práticas que já desenvolvem?

Nossa proposta se coloca na tentativa de trazer uma contribuição a esse debate, buscando problematizar o mundo do trabalho feminino, a partir da implementação de oficinas de artesania, partindo da concretude das experiências das mulheres artesãs envolvidas. Para dar conta de nossa proposta, buscamos uma aproximação teórica com o referencial advindo da teoria feminista, basicamente no que se refere à problematização histórica do mundo do trabalho feminino, aliada ao referencial da Arte, mais especificamente da arte-educação, para entender e problematizar as potencialidades criadoras do trabalho artesanal.

Em função disso, a iniciativa buscou construir um espaço de produção artesanal, onde as memórias são resgatadas não apenas a partir da oralidade, com o resgate das trajetórias vividas, mas também na produção concreta do artesanato, de forma coletiva e solidária, através do que denominamos de Oficinas de Criação Coletiva. (MEIRA, 2007).

A partir dessa perspectiva a investigação propôs, portanto, a união entre arte e educação, na figura de uma educação estética que, através da arte e seus 
processos, abre possibilidades para as abordagens autobiográficas e de criação coletiva aflorarem no próprio processo de produção. Dessa forma, as oficinas de artesanato e criação coletiva se constituem em espaços de troca de experiências, a partir da compreensão entre os envolvidos dos seus próprios processos de aprendizagens com a ressignificação de suas práticas existenciais e profissionais. Nesses encontros, buscamos a abordagem de suas histórias de vida, a partir de relatos que surgem nos encontros. Essa proposta de socialização coletiva das histórias de vida se baseia na perspectiva metodológica da pesquisa-formação, especialmente desenvolvida por Josso (2004).

Para isso, a proposta construiu um espaço de formação denominado Oficinas de Criação Coletiva, que se constituiu em um espaço de coleta de dados empíricos, sensíveis, expressivos e onde afloraram as histórias de vida que são tecidas junto com os trabalhos das mulheres pois, de acordo com Delory-Momberger (2012), não há vida humana sem narrativa, pois as pessoas vivem suas vidas, contando-as, tanto para si mesmas como para os outros. Não há vida sem narrativa porque não há humanidade sem história. E a história é contada a partir das narrativas, pois são elas que visibilizam as experiências vividas.

Partindo desse desenho, engendramos a implementação das Oficinas de Criação Coletiva, realizadas no espaço da Universidade onde, coletivamente, trocamos experiências e aprendizagens. Estimula-se nesse espaço a criação de um grupo afetivo e de convivência onde o prazer dos sentidos e a criação não são privilégio da arte, mas da vida e sua "conjunção sensualista", que lhe confere "unicidade", "composição entre razão/emoção", como anota Maffesoli (1996, p. 74). Portanto, considera o prazer, mais especificamente, o prazer "de sentir".

Meira (2007) aponta que a principal característica pedagógica das Oficinas de Criação Coletiva seria possibilitar perceberem-se as tensões, as vibrações, os silêncios, muitos deles não captáveis desde a razão ou sob códigos e explicações convencionais. Assim, se pode almejar ser mais criativo, podendo melhor construir projetos de cidadania, cuidado, atendendo às mais diversas necessidades. E, dessa forma, provocar a criação no outro.

\section{A contribuição dos estudos de gênero}

Desde a pré-história, quando os seres humanos criaram seus primeiros instrumentos de pedra, passando por todas as sociedades da antiguidade e pela Idade Média até o século XVIII, a produção artesanal dominava o mundo produtivo. 
A lógica do capital, implementada fortemente via Revolução Industrial, suplantou o artesanato, valorizando a produção em massa propiciada pelo maquinário. Dessa forma, não apenas o trabalho mudou, mas toda a sociedade se transformou a partir da implementação do capitalismo e da acumulação. Essa mudança criou uma ruptura entre criação e produção, ou seja, "[...] enquanto os artesãos criavam o que produziam, os operários contratados pelas novas fábricas eram incapazes de criar (e jamais estimulados a isso!), limitando-se a operar as máquinas que fabricavam em série os produtos [...]”. (KUBRUSLY; IMBRIOSI, 2011, p. 11).

No que se refere à participação das mulheres no mercado de trabalho, sabe-se que isso acorreu bem tardiamente. Perrot (2007) ressalta dois momentos históricos como sendo desencadeadores desse processo, que foram: a Revolução Industrial (mais timidamente) e a Primeira Guerra Mundial ${ }^{3}$. Até esses momentos, podemos afirmar que cabia às mulheres sua participação apenas nos espaços domésticos, e as atividades produtivas com as quais se envolviam se referiam a esse espaço específico.

Abordar a temática do trabalho feminino nos remete à necessidade de definirmos a concepção de trabalho à qual nos aliamos. Isso se deve ao fato de que as concepções tradicionais sobre trabalho formal e/ou mercado de trabalho não dão conta de uma diversidade de atividades historicamente exercidas por mulheres e que, muitas vezes, 'escapam' das estatísticas oficiais. Dessa forma, há a necessidade de ressignificarmos esse conceito, incorporando e nos apropriando de elementos advindos de uma produção específica com esse intuito, especialmente oriundos da teoria feminista. Trata-se de um campo de estudos que está longe de esgotar sua produção, mas que aponta vários caminhos promissores.

Dessa forma, podemos afirmar que as mulheres sempre trabalharam, embora seu trabalho tenha sido desvalorizado pelo capitalismo, que passa a valorizar as atividades que geram mais-valia e que são executadas em espaços públicos, menosprezando-se o espaço doméstico. Por isso nos aproximamos do conceito de divisão sexual do trabalho (HIRATA, 2002; HIRATA; KERGOAT, 2007; KERGOAT, 2003), que dá conta das atividades exercidas historicamente por mulheres e, além disso, reconhece que a divisão social do trabalho é marcada pelas diferenças de gênero, pois "o contexto em que vivem homens e mulheres não é o resultado de um 'destino' biológico, mas sim de construções sociais". (SILVA, 2011, p. 115).

O conceito de divisão sexual do trabalho, localizado dentro da lógica da teoria feminista, tem sido um importante suporte teórico que possibilita a

$3 \mathrm{O}$ contexto de ingresso das mulheres no mercado de trabalho formal é melhor detalhado em Silva (2011). 
abordagem das trajetórias de gênero e de trabalho feminino. Precisamos ter em mente que o contexto em que vivem homens e mulheres não é o resultado de um destino biológico, como historicamente tentou-se supor, mas sim oriundo de construções sociais. Portanto, homens e mulheres formam dois grupos sociais que estão engajados em uma relação social específica, que se concretiza nas relações sociais de sexo. Estas relações possuem uma base material, que é o trabalho, e que se revela através da divisão social do trabalho entre os sexos, denominada de divisão sexual do trabalho.

Portanto, identificamos o conceito de divisão sexual do trabalho como central na abordagem do trabalho feminino e salientamos aqui duas autoras como sendo fundamentais, dada a importância de suas produções sobre o tema, que são Danièle Kergoat e Helena Hirata.

Sobre a origem do conceito de divisão sexual do trabalho, Danièle Kergoat (2003) salienta que essa noção foi utilizada, primeiramente, por etnólogos para designar uma divisão "complementar" das tarefas entre os homens e as mulheres nas sociedades que eles estudavam. Refere-se a Lévi-Strauss como sendo um expoente dessa ideia e que fez dela o instrumento explicativo da estruturação da sociedade em família. No entanto, a autora afirma que foram as antropólogas feministas, as primeiras que lhe deram um conteúdo novo, demonstrando que ela traduzia não uma complementaridade de tarefas, mas uma relação de poder dos homens sobre as mulheres. (HIRATA; KERGOAT, 2007).

Dessa forma, Kergoat (2003) conceitua divisão sexual do trabalho, e a define como sendo:

[...] a forma de divisão do trabalho social decorrente das relações sociais de sexo; essa forma é adaptada historicamente e a cada sociedade. Ela tem por características a destinação prioritária dos homens à esfera produtiva e das mulheres à esfera reprodutiva e, simultaneamente, a apreensão pelos homens das funções de forte valor social agregado (políticas, religiosas, militares etc.). (KERGOAT, 2003, p. 55-56).

É dessa forma que percebemos a produção artesanal exercida pelas mulheres que participam da investigação que acompanhamos: trata-se da realização de trabalhos que foram (e ainda são!) historicamente apartados dos espaços públicos e desconsiderados pela lógica do capital. Pensamos que o artesanato passe por uma dupla exclusão pois, por um lado, constitui-se em uma atividade que não se adequou à produção industrial em massa (alicerce do capitalismo industrial) por sua característica de trabalho manual e criativo e, por outro lado, 
foi historicamente relegado quase que exclusivamente às mulheres e usado como forma de mantê-las atreladas ao espaço doméstico.

A compreensão de que homens e mulheres pertencentes às mais diversas sociedades se dediquem a diferentes atividades tem sido entendida como inerente à diferenciação sexual. Essa compreensão tem sido relacionada com especificidades físicas, intelectuais, emocionais, de acordo com cada sexo. É, portanto, dessa maneira que as ideologias sexistas têm compreendido a relação sexo e trabalho.

Dessa forma, as mais diversas sociedades têm criado grupos sociais distintos em função do acesso ao trabalho e do tipo de atividades, tendo se explicado como divisões naturais do trabalho, portanto, imutáveis. Em função desse caráter a-histórico e inerte, as ideologias sexistas e racistas, de cunho biológico, são as que têm se mantido por maior tempo e com maior êxito na reprodução das ordens sociais. Heleieth Saffioti (1987) tem denunciado o caráter de naturalização desse processo em sua obra já há algum tempo, conforme aparece na passagem a seguir:

A sociedade investe muito na naturalização deste processo. Isto é, tenta fazer crer que a atribuição do espaço doméstico à mulher decorre de sua capacidade de ser mãe. De acordo com esse pensamento, é natural que a mulher se dedique aos afazeres domésticos, aí compreendida a socialização dos filhos, como é natural sua capacidade de conceber e dar à luz. (SAFFIOTI, 1987, p. 9).

A homologação das atividades exercidas pelas mulheres como naturais leva a definir a essência de qualquer trabalho feminino como sexual, biológico, portanto não social. Essa concepção a-histórica e naturalista tem anulado uma diversidade de trabalhos exercidos pelas mulheres.

Sendo assim, podemos falar que divisão sexual do trabalho é muito mais do que simplesmente constatar desigualdades. É articular a descrição do real com uma reflexão sobre os processos pelos quais a sociedade utiliza a diferenciação para hierarquizar as atividades. (KERGOAT, 2003, p. 59). Buscamos que esta investigação se constitua em um desses momentos de reflexão e reconstrução, buscando sempre possibilitar uma articulação das trajetórias analisadas com o contexto social mais amplo em que essas estão inseridas.

No que se refere ao artesanato, ele permanece sendo realizado por mulheres em seus lares. Essa atividade era inclusive incentivada pela Igreja, pois se constituía numa forma pedagógica de aprendizagem dos "papéis femininos". 
Inclusive muitas escolas formais tinham o aprendizado em artesanato como parte de seu currículo. Dessa forma, portanto, o domínio dos chamados "trabalhos manuais" era fundamental para o exercício da feminilidade. Assim, temos muitas gerações de mulheres formadas nessa perspectiva. Nossa pesquisa visibiliza essa realidade, pois nos depoimentos fica claro que a aprendizagem com o artesanato se deu já na infância e com mulheres mais velhas da própria família (mães, avós, tias, etc.), como denota a passagem a seguir:

[...] a minha mãe, ela gosta muito de costura, ela tem máquina de costura, mas não é costureira profissional. Ela é curiosa, para fazer. A minha mãe faz tricô, crochê. E a minha bisavó fazia, por parte do meu pai, também crochê. E era muito legal. Tinha isso assim. Tinha perto de mim, mas não que eu chegasse a fazer. Tricô eu sei fazer, mas crochê, sempre tive vontade de fazer, mas não sei se eu acho difícil... porque todo mundo faz, diz que não é difícil, é fácil, fácil, fácil, crochê acho que é mais fácil que tricô. Mas eu tenho muita vontade de aprender, por isso meio que eu estou, entrei na oficina para aprender porque eu gosto de aprender essas coisas, lidar com artesanato, essas coisas, eu acho muito fascinante assim. E estou gostando, espero gostar mais e mais, conseguir aprender. (M., discente de Pedagogia, out. 2012).

Compreendemos que essa realidade histórica manteve o artesanato 'vivo', pois são saberes que resultaram de aprendizagens, em grande medida familiares. Dessa forma, o artesanato tem se mantido durante séculos e perdura até hoje. Por isso tratamos essa atividade com tamanho respeito porque compreendemos que falar de artesanato é, de certa forma, falar das mulheres.

Dessa forma incorporamos o artesanato em nossa pesquisa, como uma maneira de nos aproximarmos das trajetórias femininas e, mais do que isso, como uma forma metodológica de cada participante 'narrar sua história', para que a própria arte criada se constitua em um dado da investigação.

\section{As narrativas auto(biográficas) como proposta metodológica}

As histórias de vida são importantes em nossa proposta por visibilizarem as trajetórias das mulheres envolvidas. São nessas histórias que se encontram 
as raízes dos seus fazeres e de suas aprendizagens, tanto no artesanato como no que se refere aos papéis sociais de gênero que incorporam em seus cotidianos.

A metodologia utilizada nessa investigação no resgate e tratamento das narrativas auto(biográficas) é oriunda da corrente teórico-metodológica denominada pesquisa-formação, tendo como um de seus principais expoentes o referencial construído por Marie-Christine Josso. Ela participou da chamada equipe de Genebra, que também contou com a participação de Pierre Dominicé e Gaston Pineau, entre outros pesquisadores de diversos países europeus. $\mathrm{Na}$ década de 1980 do século passado, o grupo vislumbrou um novo horizonte teórico no campo da educação de adultos para uma abordagem da formação centrada sobre o sujeito aprendiz, utilizando a mediação de uma metodologia de pesquisa articulada às histórias de vida. Dessa forma nascia a pesquisa-formação.

A proposta de Josso (2004) de se perceber o processo de investigação como um 'caminhar para si' ${ }^{4}$ denota o processo inconcluso de uma investigação, ao mesmo tempo em que nos remete à nossa própria trajetória de vida neste mundo. Sobre o conceito 'caminhar para si', Josso (2004) afirma que:

O processo do caminhar para si apresenta-se, assim, como um projeto a ser construído no decorrer de uma vida, cuja atualização consciente passa, em primeiro lugar, pelo projeto de conhecimento daquilo que somos, pensamos, fazemos, valorizamos e desejamos na nossa relação conosco, com os outros e com o ambiente humano e natural. (JOSSO, 2004, p. 59).

É pela palavra e pela atividade de rememoração que as envolvidas na pesquisa não apenas revelam a sua opinião, mas encontram a oportunidade de indagar a si mesmas sobre o que lhes é perguntado. As questões de pesquisa passam a ser perguntas para que possam pensar, lembrar, relacionar fatos e conscientizar-se, mesmo que essa tomada de consciência seja algo provisório e que seja questionada mais adiante.

Sobre questões de pesquisa, salientamos alguns pontos importantes levantados por esta metodologia e citados por Delory-Momberger (2008):

Como se encontram o mundo de experiências, figuras e expectativas que a criança, o jovem e o adulto em formação trazem con-

4 Conceito desenvolvido por Josso em sua tese de doutorado, publicada em 1991 com este nome. No Brasil a tese "Caminhar para si" foi publicada como livro de mesmo nome somente em 2010 pela editora da PUC/RS. 
sigo, e o mundo de conhecimentos que as instituições educativas propõem? Existe uma relação entre a forma como os indivíduos representam sua vida e a maneira como eles adquirem competências e saberes sobre o mundo e sobre si mesmos? Como a família, a escola e a sociedade elaboram modelos e trajetórias de formação? Como os indivíduos constroem subjetivamente o percurso e a imagem de sua existência? (DELORY-MOMBERGER, 2008, p. 25).

Nessa perspectiva, percebemos o biográfico "como uma categoria da experiência que permite ao indivíduo, nas condições de sua inscrição sócio-histórica, integrar, estruturar, interpretar as situações e os acontecimentos vividos". (DELORY-MOMBERGER, 2008, p. 26). No entanto, a autora nos alerta, e é importante ressaltarmos aqui, que essas experiências que compõem o mosaico das biografias humanas não são, de forma alguma, experiências individuais e espontâneas. Elas "trazem a marca de sua inscrição histórica e cultural e têm origem nos modelos de figuração narrativa e nas formas de relação do indivíduo consigo mesmo e com a coletividade, elaborados pelas sociedades nas quais se inscrevem". (DELORY-MOMBERGER, 2008, p. 27).

Delory-Momberger (2008) em sua obra denomina sua metodologia de pesquisa-formação como "ateliê biográfico de projeto". Adaptando a ideia para nossa experiência de projeto, desenvolvemos o conceito de "ateliê biográfico de artesania", nos referindo aos momentos coletivos de produção artesanal.

Os "ateliês biográficos de artesania" dizem respeito às produções artesanais materializadas em oficinas que possibilitam a troca de experiências no que se refere às aprendizagens em artesanato, possibilitando, dessa forma, momentos de trocas de vivências entre os dois grupos participantes. Essa iniciativa surge com a intenção de valorizar e assumir a incorporação dessas atividades produtivas na constituição das identidades femininas em questão. Incorpora-se na perspectiva de valorização das experiências de trabalho das mulheres. A forma metodológica adotada nas oficinas tem sido a forma proposta por Meira (2007), denominada de Oficina de Criação Coletiva, que possibilita a construção de saberes partindo de vivências para chegar à consciência e ao conhecimento em arte e saberes estéticos, tão cognitivos quanto qualquer outro.

Josso (2004), além de desenvolver estudos e pesquisas sobre histórias de vida em formação, também é pintora profissional. No prefácio do livro de Souza e Abrahão (2006) ela aborda esse contexto e relata que demorou um tempo e precisou de um certo distanciamento para perceber a relação entre essas duas atividades pois, ao mesmo tempo que fazia sua tese de doutorado, pintava e 
participava de exposições. Hoje tem consciência de que a atividade artística desenvolvida por ela inscreve-se totalmente na perspectiva autobiográfica, onde um polo influenciava o outro diretamente, conforme ela demonstra na passagem a seguir, quando diz que:

Assim, o trabalho biográfico permitiu criar um discurso que, ao se fazer, inventou a parte original de minha identidade de pesquisadora profissional e nutriu-se de outras atividades tais como o meu trabalho de pintora e me ajudou a inventar a especificidade de minha identidade de artista profissional. (JOSSO apud SOUZA; ABRAHÃO, 2006, p. 10).

É dessa forma que percebemos os "ateliês biográficos de artesania", como a materialização de um espaço que permita aos seus integrantes explorar e criar, através de suas próprias trajetórias como parte do processo de formação, constituindo a "invenção de si" num projeto formador de suas vidas. A expressão através da arte sensível é parte constituinte das biografias, concretizando outra ferramenta, além da oralidade e da escrita, para compor as histórias de vida.

\section{Considerações finais}

Na pesquisa percebemos que as narrativas sobre a aprendizagem artesanal têm cumprido o papel de desvelar as trajetórias de vida das mulheres envolvidas. A maioria aprendeu o artesanato inicialmente na infância, nos espaços domésticos e vinculados às relações familiares, onde as figuras femininas (mães, avós, tias, irmãs, etc.) são majoritárias em suas aprendizagens com o artesanato. Enfim, são diversas histórias de vida que visibilizam trabalhos femininos, em que o artesanato tem tido papel de destaque.

A pesquisadora mexicana Marcela Lagarde y de los Rios (2005) desenvolve a categoria de 'madresposa', que sintetiza muito bem o papel social exercido pelas mulheres, em grande parte girando ao redor da conjugalidade e da maternidade. Nesse contexto, tão vinculado ao espaço doméstico, encontramos o trabalho artesanal, enquanto atividade 'invisível' e desvalorizada socialmente. $\mathrm{Na}$ perspectiva que adotamos, compreendemos que no artesanato produzido estão também suas trajetórias, pois a produção artesanal é uma forma de narrativa (auto)biográfica. 
A pesquisa está em fase de execução, em que estamos realizando Oficinas e coletando narrativas autobiográficas do grupo. No entanto, já é possível fazer algumas inferências sobre o processo que estamos implementando.

As mulheres que fazem parte da investigação buscam, de várias formas, visibilidade e valorização social de seus trabalhos artesanais. De acordo com Silva e Eggert (2011), "na contracorrente de interpretações que percebem o artesanato como mais um instrumento de dominação feminina, pensamos que ele pode ser um poderoso instrumento de criatividade, elaboração subjetiva, autonomia e formação política [...]". (SILVA; EGGERT, 2011, p. 58).

$\mathrm{Na}$ vida social a criação coletiva é uma espécie de matéria viva de uma obra de arte primordial, que transforma a estética da existência em uma ética do estar-junto-com-os-outros-no-mundo, pois pode "a potência coletiva" criar "uma obra de arte: a vida social em seu todo, e em suas diversas modalidades". (MAFFESOLI, 1996, p. 28). É dessa forma que compreendemos as Oficinas de Criação Coletiva que a pesquisa tem implementado.

Sobre o sensível como parte integrante de nosso processo de formação, Josso nos diz que:

Essa consideração das diferentes formas do sensível, em nossa formação, permite fazer emergir dimensões escondidas de si que re-dinamizam um projeto porque recompõem os recursos e uma coerência pessoal. Pode-se também se projetar, se identificar e introjetar aspectos do que esse sensível nos oferece para ver, sentir, pensar, fazer, etc. Há ainda aí uma dinamização e uma invenção de si em novas perspectivas, em novas formas, a arte como via de conhecimento. (JOSSO apud SOUZA; ABRAHÃO, 2006, p. 11).

Fazer arte no contexto das Oficinas é um fazer com um propósito significativo para elas, uma porta para perceberem a educação como algo além da "decoreba" e do "fazer por fazer". A cada encontro, elas urdiam em suas tramas o que estava acontecendo no dia, o que aconteceu há pouco tempo ou há muito tempo atrás, o que poderia acontecer e o que caracterizava cada personagem significante em suas vidas. Como exemplo de tantos depoimentos, segue o seguinte fragmento:

[...] quando eu comecei a tear, veio à memória toda a minha empolgação quando eu fazia blusas, crochês, aprendi os pontos, aprendendo a bordar. Então tudo isso retomou, então foi aí que eu percebi que eu sempre gostei 
do artesanato, só que eu deixei escondido. Agora, com a volta, fazendo mestrado em Artes, trazendo o artesanato eu percebi que o artesanato sempre foi minha paixão. Sempre foi! Eu acho que, eu não sei, ouvia muito o pessoal tem muito preconceito em relação a isso, na Academia eu sinto muito isso, acho que ficou meio escondido, né. Eu não sei se foi uma forma de me proteger... (M., professora de arte e mestranda em artes visuais, 30.06.2012).

Dessa forma, as ressignificações da artesania apontaram um novo olhar sobre o material que elas utilizam e sobre a forma como produzem, dando novos significados. Perceberam que a artesania pode ser Arte, não necessariamente "algo utilitário", com uma "receita" para compor, mas permite experienciar, perceber os materiais, senti-los, transformá-los... E entenderem que o processo de sua interação com os objetos e seu mundo, assim como com as pessoas à sua volta, pode ser tramado. Trabalhar com esses conhecimentos a partir de uma trama lhes permitiu perceber que arte é isso, ela está no cotidiano, nos gostos, nas experiências estéticas da vida que se derrama nas linhas e nos fios que transbordam em suas mãos.

No que se refere à participação das pesquisadoras nessa experiência, trazemos a contribuição de Wright Mills, especialmente quando se refere à produção intelectual do artesanato, desenvolvendo a categoria de "artesanato intelectual" em sua obra, enquanto modelo idealizado de satisfação no trabalho. Mills (2009) identifica seis características no artesanato, que são:

[...] não há nenhum motivo velado em ação além do produto que está sendo feito e dos processos de sua criação. Os detalhes do trabalho diário são significativos porque não estão dissociados, na mente do trabalhador, do produto do trabalho. O trabalhador é livre para controlar sua própria ação de trabalho. O artesão é, por conseguinte, livre para aprender com seu trabalho, e para usar e desenvolver suas capacidades e habilidades na execução do mesmo. Não há ruptura entre trabalho e diversão, ou trabalho e cultura. O modo como o artesão ganha seu sustento determina e impregna todo o seu modo de vida. (MILLS, 2009, p. 59).

Nesse sentido, perceber o trabalho de pesquisa como um "artesanato intelectual" ressalta a importância da dimensão existencial na atividade do(a) pesquisador(a). Isso significa que devemos aprender a reconhecer nossas experiências de vida no trabalho intelectual, interpretando-a continuamente, pois 
"dizer que você pode ter experiência significa, por exemplo, que seu passado influencia e afeta seu presente, e que ele define sua capacidade de experiência futura". (MILLS, 2009, p. 22).

\section{REFERÊNCIAS}

DELORY-MOMBERGER, Christine. Biografia e Educação: figuras do indivíduo-projeto. Natal: EDUFRN; São Paulo: Paulus, 2008.

DELORY-MOMBERGER, Christine. A condição biográfica: ensaios sobre a narrativa de si na modernidade avançada. Natal: EDUFRN, 2012.

HIRATA, Helena. Nova divisão sexual do trabalho? Um olhar voltado para a empresa e sociedade. São Paulo: Boitempo, 2002.

HIRATA, Helena; KERGOAT, Danièle. Novas configurações da divisão sexual do trabalho. Cadernos de Pesquisa, v. 37, n. 132, p. 595-609, set./dez. 2007.

JOSSO, Marie-Christine. Experiências de vida e formação. São Paulo: Cortez, 2004.

KERGOAT, Danièle. Divisão sexual do trabalho e relações sociais de sexo. In: EMÍLIO, Marli et al. (Orgs.). Trabalho e cidadania ativa para as mulheres: desafios para as políticas públicas. São Paulo: Coordenadoria Especial da Mulher, 2003. p. 55-63.

KUBRUSLY, Maria Emilia; IMBRIOSI, Renato. Desenho de fibra: artesanato têxtil no Brasil. Rio de Janeiro: SENAC, 2011.

LAGARDE Y DE LOS RIOS, Marcela. Los cautiveros de las mujeres: madresposas, monjas, putas, presas y locas. 4. ed. México: UNAM, 2005.

MAFFESOLI, Michel. No Fundo das Aparências. Petrópolis, RJ: Vozes, 1996.

MEIRA, Mirela. Metamorfoses Pedagógicas do Sensivel e suas Possibilidades em "Oficinas de Criação Coletiva". 157 f. Tese (Doutorado em Educação) - Faculdade de Educação, Universidade Federal do Rio Grande do Sul, Porto Alegre, 2007.

MILLS, Charles Wright. Sobre o artesanato intelectual e outros ensaios. Rio de Janeiro: Jorge Zahar Ed., 2009.

PERROT, Michelle. Minha história das mulheres. São Paulo: Contexto, 2007.

SAFFIOTI, Heleieth. O poder do macho. São Paulo: Moderna, 1987.

SILVA, Márcia Alves da. "Confeccionando" reflexões sobre o trabalho feminino artesanal. In: SILVA, Márcia Alves da (Org.). Gênero, sexualidade, educação e conhecimento. Pelotas: Editora da UFPel, 2011. 
SILVA, Márcia Alves da; EGGERT, Edla. Descosturar o doméstico e a 'madresposa' - a busca da autonomia por meio do trabalho artesanal. In: EGGERT, Edla (Org.). Processos educativos no fazer artesanal de mulheres do Rio Grande do Sul. Santa Cruz do Sul: EDUNISC, 2011. p. 41-59.

SOUZA, Elizeu Clementino de; ABRAHÃO, Maria Helena Menna Barreto (Orgs.). Tempos, narrativas e ficções: a invenção de si. Porto Alegre: EDIPUCRS; Salvador: EDUNEB, 2006.

Texto recebido em 12 de junho de 2014. Texto aprovado em 16 de março de 2015. 